\title{
Ghrelin regulates sepsis-induced rat acute gastric injury
}

\author{
BIN LI $^{1}$, QINGLING LIN ${ }^{2}$, HONG GUO $^{2}$, LIPING LIU ${ }^{2}$ and YUMIN LI ${ }^{1}$ \\ ${ }^{1}$ Department of General Surgery, The Second Hospital of Lanzhou University; ${ }^{2}$ Department of \\ Intensive Medicine, The First Hospital of Lanzhou University, Lanzhou, Gansu 730000, P.R. China
}

Received July 24, 2018; Accepted March 26, 2019

DOI: $10.3892 / \mathrm{mmr} .2019 .10208$

\begin{abstract}
Ghrelin, a peptide expressed in the gastric mucosa, has an essential role in sustaining the normal function of the digestive system. Sepsis is one of the primary causes of mortality in intensive care units and can lead to multiple organ dysfunction, especially in the gastrointestinal system. The aim of the present study was to explore the effect of ghrelin on gastric blood flow in a rat model of sepsis, as well as the effect of ghrelin on the expression of the apoptotic markers, B-cell lymphoma 2 (Bcl-2) and Bcl-2-associated X (Bax), in gastric tissues. The sepsis model was established using cecal ligation and puncture (CLP). The expression levels of apoptosis-related factors in gastric epithelial cell were determined by immunohistochemistry, reverse transcription quantitative-PCR and western blotting. Collectively, the present results suggested that ghrelin administration attenuated sepsis symptoms induced by CLP. Blood flow in the stomach greater curvature was significantly higher in the CLP-induced sepsis group rats $(284.3 \pm 95.7$ perfusion units) compared with the sham operation group $(317.8 \pm 5.2$ perfusion units; $\mathrm{P}<0.05)$, whereas there was no difference between the CLP group treated with ghrelin (377.8 \pm 99.0 perfusion units) and the sham rats. Ghrelin administration also reduced the secretion of pro-inflammatory cytokines compared with the CLP-induced sepsis group rats. In addition, CLP significantly reduced the expression of Bcl-2 and enhanced the expression of the pro-apoptotic proteins, Bax and cleaved caspase-3; whereas, ghrelin application reversed the effects of CLP on these apoptosis-associated proteins. In conclusion, the present study revealed that ghrelin has the ability to increase blood flow in the gastrointestinal tract in a sepsis model and can also regulate the expressions of apoptosis-associated factors in gastric tissues. These results suggest that ghrelin could be a novel treatment for sepsis-induced gastric injury.
\end{abstract}

Correspondence to: Professor Yumin Li, Department of General Surgery, The Second Hospital of Lanzhou University, 82 Cuiyingmen, Lanzhou, Gansu 730000, P.R. China

E-mail: lynd0001@163.com

Key words: ghrelin, sepsis, stomach, blood flow, apoptosis

\section{Introduction}

Sepsis is a systemic inflammatory response syndrome that can be caused by invading pathogens (1-3). Severe sepsis leads to multiple organ dysfunction and circulatory failure (1-3). Despite significant advances in the understanding of the mechanisms of sepsis, it remains one of the major causes of patient mortality in intensive care units. Sepsis is a common critical condition that is difficult to treat and has a high mortality rate $(4,5)$. In the United States, the incidence of severe sepsis is estimated to be 300 cases per 100,000 of the population, and the age-adjusted mortality caused by sepsis is $>60$ per $100,000(6)$. Sepsis is associated with gastrointestinal tract dysfunction, manifesting as dysfunction in gastrointestinal motility, nutritional absorption and the intestinal immunological barrier, which ultimately results in intestinal mucosa atrophy, dysbacteriosis and enterogenic infection, thereby causing or aggravating dysfunction in other organs $(7,8)$. Hiltebrand et al (9) reported that stomach blood flow was reduced by 55\% in a sepsis model in pigs. Lang et al (5) also reported decreased cardiac output during sepsis, and a similar observation has been made in humans (10-12).

Ghrelin, which is predominantly secreted by the gastric mucosa $(\sim 67 \%)$ and intestinal mucosa $(\sim 33 \%)(13-17)$, mediates its effect by binding to growth hormone secretagogue receptor-1a (15). Ghrelin has a vital role in regulating appetite, promotes ingestion, increases body weight, improves gastric contraction function, increases small intestine transportation, promotes the secretion of growth hormones and improves gastric mucosal blood flow (18-20). Ghrelin may have some therapeutic potential for treating gastrointestinal dysfunction in patients with diabetic gastroparesis and in the ileus post-surgery (21). The protective effects of ghrelin in the stomach are reported to be due to improved blood flow mediated by prostaglandins and nitric oxide in a healthy rodent model $(22,23)$. Additionally, ghrelin has been shown to suppress intestinal mucosal apoptosis in a non-inflammatory animal model (24). However, it is not clear whether the administration of ghrelin has a beneficial effect on sepsis-induced gastric system complications. Therefore, the present study aimed to explore the effects of ghrelin on gastric blood flow and disease severity in septic rats, and investigated the potential mechanisms by which ghrelin regulates the expression of apoptosis-associated factors in gastric tissues. 


\section{Materials and methods}

Animals. Healthy male Wistar rats $(n=36)$ aged 6-8 weeks and weighing 180-250 g were purchased from the Gansu University of Traditional Chinese Medicine (Lanzhou, China). Animals were maintained under pathogen-free conditions at the animal facility of Lanzhou University (Lanzhou, China). Rats had free access to food and water and they were maintained under a 12-h light/dark cycle at room temperature with $50-65 \%$ relative humidity. All procedures involving mice were approved by the Institutional Animal Care and Use Committee of Lanzhou University.

Development of sepsis. The rats were randomly divided into 3 groups ( $n=12 /$ group): Sham group, sepsis group and ghrelin group. The rats in the sham group received sham surgery. Rats in the sepsis and ghrelin groups underwent cecal ligation and puncture (CLP) surgery to induce the sepsis model $(25,26)$. Briefly, rats were fasted for $12 \mathrm{~h}$ and intraperitoneally injected with $1 \%$ pentobarbital sodium (50 mg/kg; production batch number wS20160401; West of Shanghai Tang Biotechnology Co., Ltd., Shanghai, China) for anesthesia prior to surgery. Following conventional disinfection, a $2-\mathrm{cm}$ incision was made along the abdominal medial line. The cecum was circumferentially ligated $0.5 \mathrm{~cm}$ away from the ileocecal valve using 3/0 suture. An 18-gauge syringe needle was used to cut through the cecum twice. The intestinal contents were slightly pushed out by gently squeezing the intestinal canal. The cecum was returned to its original site, and the incision was sutured layer-by-layer. Sterile saline $(3 \mathrm{ml} / 100 \mathrm{~g})$ was immediately subcutaneously injected to compensate for the loss of body fluid. For the rats in the sham group, after locating the cecum, the intestine was placed outside of the abdomen for $2 \mathrm{~min}$ and then returned to the abdominal cavity.

Ghrelin (Enzo Life Sciences, Inc., Farmingdale, NY, USA) was dissolved in saline $(1 \mathrm{ml})$ and injected intraperitoneally at $13.3 \mathrm{nmol} / \mathrm{kg} /$ injection in the ghrelin group rats at 2, 4 and $8 \mathrm{~h}$ post-surgery, following a previously established protocol $(27,28)$. The rats in the sham and sepsis groups were injected with $1 \mathrm{ml}$ saline at the same time points as the ghrelin group rats following surgery.

Blood pressure monitoring. Blood pressure in the 3 groups of rats was measured at the tail base $2 \mathrm{~h}$ post-surgery using a non-invasive blood pressure system (IITC Life Science, Inc., Woodland Hill, CA, USA) according to the manufacturer's instructions. Rats were fixed in place using rat fixing apparatus (DCX II; JiXi RuiJi BioTechnology Co., Ltd.).

Gastric perfusion imaging. A laser Doppler perfusion imaging instrument (PeriScan PIM 1I; Perimed AB, Järfälla, Sweden) was used to assess rat blood flow in the greater curvature of the stomach. The laser wavelength used was $670 \mathrm{~nm}$. The NR scanning mode and Min scanning accuracy were used in this experiment. The imaging range was set at $25 \times 30 \mathrm{~mm}$, and pixel size was $0.5 \mathrm{x} 0.5 \mathrm{px}$. LDPI imaging software (version 2.5; Perimed AB, Järfälla, Sweden) was used to record, analyze and process gastric blood flow images. The unit of blood flow was expressed as perfusion units.
Levels of systemic and local ghrelin and inflammatory factors assay. At $24 \mathrm{~h}$ following the operation, sera collected from each experimental group were diluted and used in ELISAs to measure protein levels. The rat gastrointestinal tract from the stomach to the duodenum was isolated, and the food debris was carefully removed under a dissection microscope. One part of the tissue was mechanically homogenized in radioimmunoprecipitation assay (RIPA) lysis buffer (Santa Cruz Biotechnology, Inc., Dallas, TX, USA) containing protease inhibitors. The homogenized tissue was incubated on ice for $45 \mathrm{~min}$ with brief vortexing every $5 \mathrm{~min}$. Tissue lysates were centrifuged at $4,000 \times \mathrm{g}$ for $40 \mathrm{~min}$ at $4^{\circ} \mathrm{C}$, the pellets were discarded and protein concentration of the supernatant was measured using the Pierce Bicinchoninic Acid Protein Assay kit (Thermo Fisher Scientific, Inc., Waltham, MA, USA). The serum (systemic) and protein lysate (local) ghrelin levels were then measured using a Colorimetric Rat Ghrelin ELISA kit (cat. KA1863; Bio-Techne, Minneapolis, MN, USA). The levels of inflammatory factors [tumor necrosis factor (TNF)- $\alpha$, interleukin (IL)-1 $\beta$ and IL-6] were measured using the Rat Inflammation ELISA Strip (cat. no. EA-1201; Signosis, Inc., Santa Clara, CA, USA) and Rat IL-10 ELISA Kit (cat. no. RAB0246; Merck KGaA, Darmstadt, Germany) according to the manufacturer's protocol. The final local inflammatory factor concentrations were normalized to the starting initial protein concentration.

Isolation of rat primary gastric epithelial cells (GECS). Rat GECs were isolated as previously described $(29,30)$. Briefly, bacterial contaminants were removed from the remaining part of the collected tissue (incubated in $50 \mathrm{ml} 0.04 \%$ sodium hypochlorite on ice for $15 \mathrm{~min}$ ). The tissue was minced and incubated in $1 \%$ pronase (Sigma-Aldrich; Merck KGaA, Darmstadt, Germany) dissolved in $1 \mathrm{XPBS}$ for $2 \mathrm{~h}$ at $37^{\circ} \mathrm{C}$. The cells were then treated with DNase I for $40 \mathrm{~min}$ at $37^{\circ} \mathrm{C}$, washed with ice-cold buffer and centrifuged at $1,000 \mathrm{x} \mathrm{g}$ for $5 \mathrm{~min}$ at $4^{\circ} \mathrm{C}$. The cells were then filtered with $40-\mathrm{mm}$ nylon cell mesh and washed with PBS three times at room temperature, and then cultured in epithelial cell culture medium. The isolated GECs were validated using specific markers anti-CD45 (1:200; cat. no. 202201; Biolegend, Inc., San Diego, CA, USA) and anti-CD103 (1:200; cat. no. 205505; Biolegend, Inc.) that were incubated for $30 \mathrm{~min}$ on ice. Flow cytometry was performed using a flow cytometer (FACSCanto II; BD Bioscience, San Jose, CA), and analyzed using the BD FACSDiva software (version 7.0; BD Bioscience).

Immunohistochemistry and immunofluorescence staining. Tissues were embedded in Optimal Cutting Temperature compound solution and immediately frozen in dry ice/ethanol bath and stored at $-80^{\circ} \mathrm{C}$. Sections ( $4 \mu \mathrm{m}$ in thickness) were prepared using a freezing microtome (wi78174; Leica Microsystems GmbH, Wetzlar, Germany). Tissue sections (thickness, $4 \mu \mathrm{m}$ ) were deparaffinized at room temperature with $100 \%$ xylene for $5 \mathrm{~min}$ and rehydrated at room temperature using descending ethanol series (100, 95, 80 and 70\% ethanol). Each incubation in ethanol was performed at room temperature for $3 \mathrm{~min}$. The sections were then subjected to antigen retrieval (citrate buffer; $10 \mathrm{mmol} / \mathrm{l}$; $\mathrm{pH}$ 6.0) for $15 \mathrm{~min}$ at room temperature. The samples were blocked with 
5\% goat serum (1:50; cat. no. GTX30973; GeneTex, Inc.) for 10-15 $\mathrm{min}$ at room temperature. Primary antibodies anti Bcl-2 (1:100; cat. no. EKC1055; Wuhan Boster Biological Technology, Ltd.) and $\operatorname{Bax}$ (1:100; cat. no. M00183-2; Wuhan Boster Biological Technology, Ltd.) were incubated overnight at $4^{\circ} \mathrm{C}$. After washing with PBS ( $\mathrm{pH} 7.2-7.6$ ), biotin-labeled goat anti-rabbit immunoglobulin $\mathrm{G}$ was added and incubated at room temperature for 10-15 min. Horseradish peroxidase-labeled streptavidin working solution was incubated with the samples at room temperature for $10 \mathrm{~min}$. After washing with PBS, staining was visualized with $0.01 \%$ 3,3'-diaminobenzidine tetrahydrochloride for $5 \mathrm{~min}$ and counterstained with $0.05 \%$ hematoxylin for 6-10 sec at room temperature. Positive was detected using a SABC-POD kit according to the manufacturer's protocol (Wuhan Boster Biological Technology, Ltd., Wuhan, China). Primary antibodies against Bcl-2 (cat. no. EKC1055) or Bax (cat. no. M00183-2) were purchased from Wuhan Boster Biological Technology, Ltd. Primary antibodies (1:100 dilution) were incubated with sections at $4^{\circ} \mathrm{C}$ overnight, then the SuperPicture $^{\mathrm{TM}}$ 3rd Gen IHC Detection kit (Thermo Fisher Scientific, Inc.) was used to detect the protein signal. For cleaved caspase-3 detection, immunofluorescent staining was performed. Primary rabbit anti-cleaved caspase-3 (cat. no. 9664; Cell Signaling Technology, Inc.) was incubated with the sections for $2 \mathrm{~h}$ at room temperature, subsequently, the SuperPicture ${ }^{\mathrm{TM}}$ 3rd Gen IHC Detection kit (Thermo Fisher Scientific, Inc.) was used to detect the protein signal according to the manufacturer's protocol. Nuclei were marked using DAPI (10 $\mu \mathrm{g} / \mathrm{ml}$; cat. no. ab228549; Abcam) at room temperature for $5 \mathrm{~min}$ in the dark.

RNA extraction and semi-quantitative polymerase chain reaction (sqPCR) detection of ghrelin. At $2 \mathrm{~h}$ following sepsis induction, GECs were isolated from the sham and CLP group rats. Total RNA was extracted from $1 \times 10^{6}$ GECs using the RNeasy RNA extraction kit (Qiagen, Inc., Valencia, CA, USA) following the kit's instructions. Extracted total RNA $(1 \mu \mathrm{g})$ from each group of rats was reverse transcribed in a $20 \mu 1$ reaction using the Superscript III reverse transcriptase (Thermo Fisher Scientific, Inc.), according to the manufacturer's instructions, with hexamer primers supplied in the kit. RT products were diluted (2-fold) in RNase-free, and 1:20 of the cDNA was used to amplify ghrelin. GAPDH was used as an internal control. The primers used in the PCR were as follows: Rat ghrelin, forward 5'TGAGCCCAGAGC ACCAGAAA3' and reverse 5'GTTGCAGAGGAGGCAGAA GCT3'; rat GAPDH, forward 5'TGAAGGTCGGTGTGA ACGGATTTGGC3' and reverse 5'CATGTAGGCCATGAG GTCCACCAC3'. PCR was performed in a $25 \mu 1 \mathrm{PCR}$ system containing $50 \mathrm{mM} \mathrm{KCl}, 10 \mathrm{mM}$ Tris- $\mathrm{HCl}, 2 \mathrm{mM} \mathrm{MgCl}_{2}$, $0.2 \mathrm{mM}$ dNTP and 0.5 units Platinum Taq DNA polymerase (Thermo Fisher Scientific, Inc.) using the following PCR program: Initial denaturation at $95^{\circ} \mathrm{C}$ for $3 \mathrm{~min}$, followed by 25 cycles of $94^{\circ} \mathrm{C}$ for $30 \mathrm{sec}, 45^{\circ} \mathrm{C}$ for $30 \mathrm{sec}$ and $72^{\circ} \mathrm{C}$ for $1 \mathrm{~min} / \mathrm{kb}$. PCR was carried out in a thermal cycler (Bio-Rad Laboratories, Inc., Hercules, CA, USA). Following reveres transcription-PCR, $10 \mu 1$ of the reaction mixture was electrophoresed on a $1 \%$ agarose gel containing ethidium bromide $(0.22 \mathrm{~g} / \mathrm{ml})$. The gel was then imaged and band intensities were normalized to GAPDH using the Bio-Rad Image System (Gel Doc XR+ System; Bio-Rad Laboratories, Inc.) and the Image Lab Software (version number 1708195; Bio-Rad Laboratories, Inc.).

Western blotting. Isolated GECs were lysed in RIPA buffer for $15 \mathrm{~min}$ on ice and cleared by centrifugation at 4,000 x g for $15 \mathrm{~min}$ at $4^{\circ} \mathrm{C}$. Protein concentration was determined using a bicinchoninic acid assay kit. Protein $(50 \mu \mathrm{g})$ was separated by $12.5 \%$ SDS-PAGE and transferred to $0.2-\mathrm{m}$ PVDF membranes. The membranes were blocked by incubation in TBS (10 mM Tris- $\mathrm{HCl}, \mathrm{pH} 7.5$ and $150 \mathrm{mM} \mathrm{NaCl}$ ) containing $5 \%$ milk for $1 \mathrm{~h}$ at room temperature. Blots were incubated with rabbit anti-Bcl-2 (cat. no. D17C4), Bax (cat. no. D3R2M) and cleaved caspase-3 (cat. no. Asp175) antibodies (1:5,000; Alpha Diagnostic International, San Antonio, TX, USA) overnight at $4^{\circ} \mathrm{C}$. The blots were then washed 3 times in TBS supplemented with $0.05 \%$ Tween for $10 \mathrm{~min}$. Blots were incubated with horseradish peroxidase-labeled secondary antibodies (cat. no. A0208; 1:3,000; Beyotime Institute of Biotechnology, Haimen, China) for $1 \mathrm{~h}$ at room temperature and then washed 3 times in TBST for $10 \mathrm{~min}$. An enhanced chemiluminescent peroxidase substrate (GE Healthcare, Chicago, IL, USA) was applied according to the manufacturer's instructions and the membranes were exposed to X-ray film. The band densities were normalized to $\beta$-actin (cat. no. 20536-1-AP; 1:5,000; Proteintech Group, Inc.) with the use of the Bio-Rad Image System (Bio-Rad Laboratories, Inc.).

Assay for GEC viability following lipopolysaccharide (LPS) stimulation. Cell viability was determined using the Annexin V Apoptosis Detection kit (BD Biosciences; Becton, Dickinson and Company, Franklin, Lakes, NJ, USA) according to the manufacturer's instructions. Fresh isolated GECs $\left(2 \times 10^{5}\right)$ from naïve rats were cultured in 24-well plates and stimulated using LPS (100 ng/ml; Sigma-Aldrich; Merck KGaA) with or without $0.1 \mathrm{nmol}$ ghrelin (Enzo Life Sciences, Inc.) for 2, 4 and 8 h. Following the incubation period, the cells were stained with $5 \mu \mathrm{l}$ Annexin $\mathrm{V}$ and propidium iodide (PI) followed by flow cytometric analysis, using a flow cytometer (LSR I; BD Bioscience). Data were analyzed using FlowJo (version X.0.7; FlowJo LLC; Ashland, OR, USA) and expressed as the percentage of Annexin V and PI-positive cells.

Statistical analysis. The results are expressed as the mean \pm standard error of the mean. SPSS 19.0 software (IBM Corp., Armonk, NY, USA) was used to analyze the data. Comparisons among groups were performed using two-way analysis of variance with the Student-Newman-Keuls-q post-hoc test. $\mathrm{P}<0.05$ was considered to indicate a statistically significant difference.

\section{Results}

Ghrelin expression is downregulated during CLP induced sepsis. To investigate the potential benefits of ghrelin administration to septic patients, a CLP-induced rat sepsis model was established in the present study, following a previously published protocol $(27,28)$. Ghrelin mRNA expression levels in 

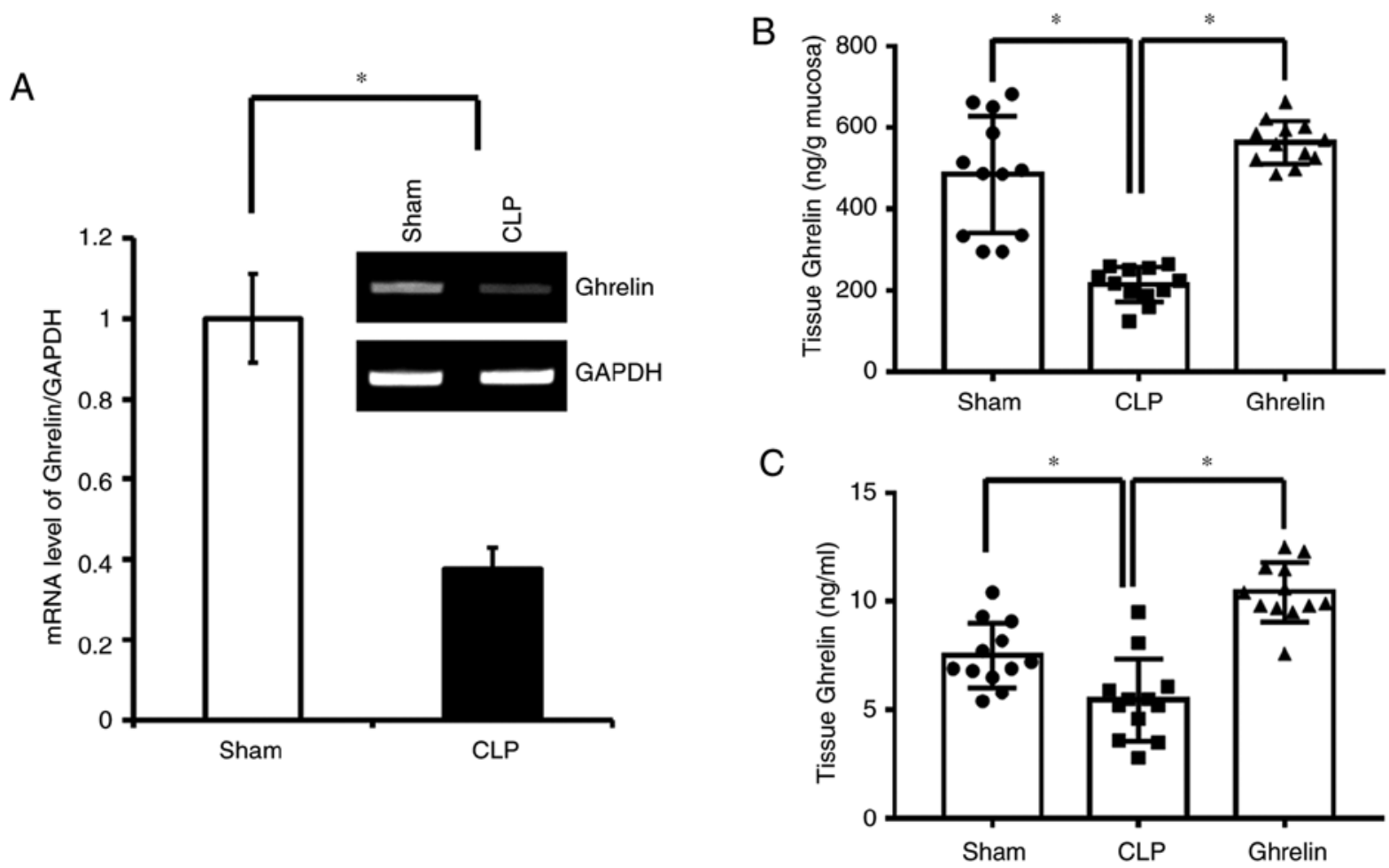

Figure 1. Ghrelin levels in the septic rat. (A) mRNA levels of ghrelin detected in the isolated gastric epithelial cells from the indicated group of the rats. A representative semi-quantitative polymerase chain reaction result is presented; 3 rats in each group were used to detect the mRNA levels in sham and CLP-treated rats. Data were normalized to GAPDH and expressed as the mean \pm standard error. (B) Ghrelin levels detected in stomach mucosa. (C) Ghrelin levels in the plasma. Each data point represents a rat. ${ }^{*} \mathrm{P}<0.05$, as indicated. CLP, cecal ligation and puncture.
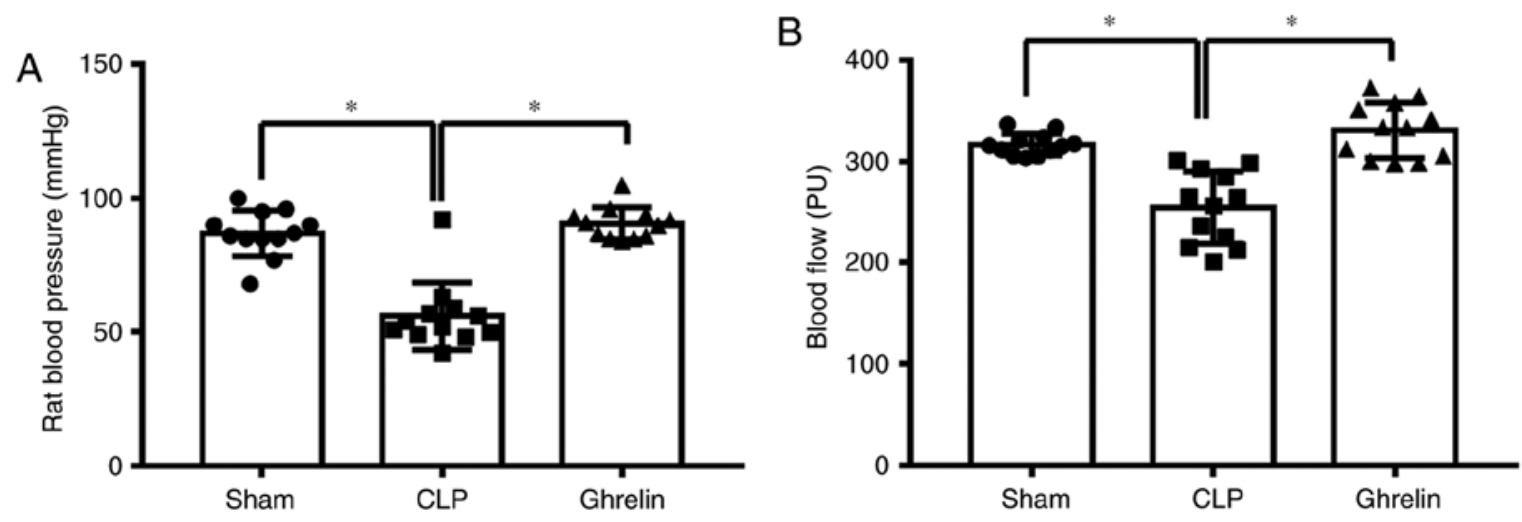

Figure 2. Tail blood pressure (mean) and blood flow in the stomach. (A) Blood pressure of rats in each group. At $2 \mathrm{~h}$ post-CLP, the tail blood pressure was measured in the rats of each group. (B) Blood perfusion to the stomach greater curvature; blood perfusion (blood flow) was monitored at $20 \mathrm{~h}$ post-CLP surgery. All data are expressed as the mean \pm standard error. Each data point represents a rat. ${ }^{*} \mathrm{P}<0.05$, as indicated. CLP, cecal ligation and puncture.

the sham and CLP group rats were determined at $2 \mathrm{~h}$ following CLP or sham surgery. At $20 \mathrm{~h}$ post-CLP and ghrelin administration, the protein levels of systemic and local ghrelin were determined by ELISA in the 3 experimental groups. As shown in Fig. 1A, at $2 \mathrm{~h}$ post-surgery, the ghrelin mRNA level was significantly lower in the CLP sepsis group than in the sham group. Consistently, at $20 \mathrm{~h}$ post-surgery, the protein level of ghrelin in the stomach tissue (Fig. 1B), where ghrelin is secreted, and the circulation (Fig. 1C) was also downregulated in the CLP sepsis rats when compared with the sham group. Notably, administration of exogenous ghrelin significantly increased the ghrelin level in the stomach mucosa and in the serum (Fig. 1B and C).
Ghrelin administration attenuates sepsis symptoms induced by CLP. The altered ghrelin expression level indicated that it may be involved in the regulation of sepsis development. It has been previously reported that ghrelin attenuates sepsis-induced acute lung injury and mortality in rats (31). Therefore, it was investigated whether ghrelin has a similar role in the gastrointestinal tract during sepsis. At $24 \mathrm{~h}$ post-CLP, blood pressure and blood flow were measured to determine the sepsis status. As shown in Fig. 2, compared with the sham group, CLP induced a significant decrease in blood pressure (Fig. 2A) and blood flow to the greater curvature of the stomach (Fig. 2B). By contrast, the blood pressure and the blood flow were increased in the ghrelin-treated group when compared with 

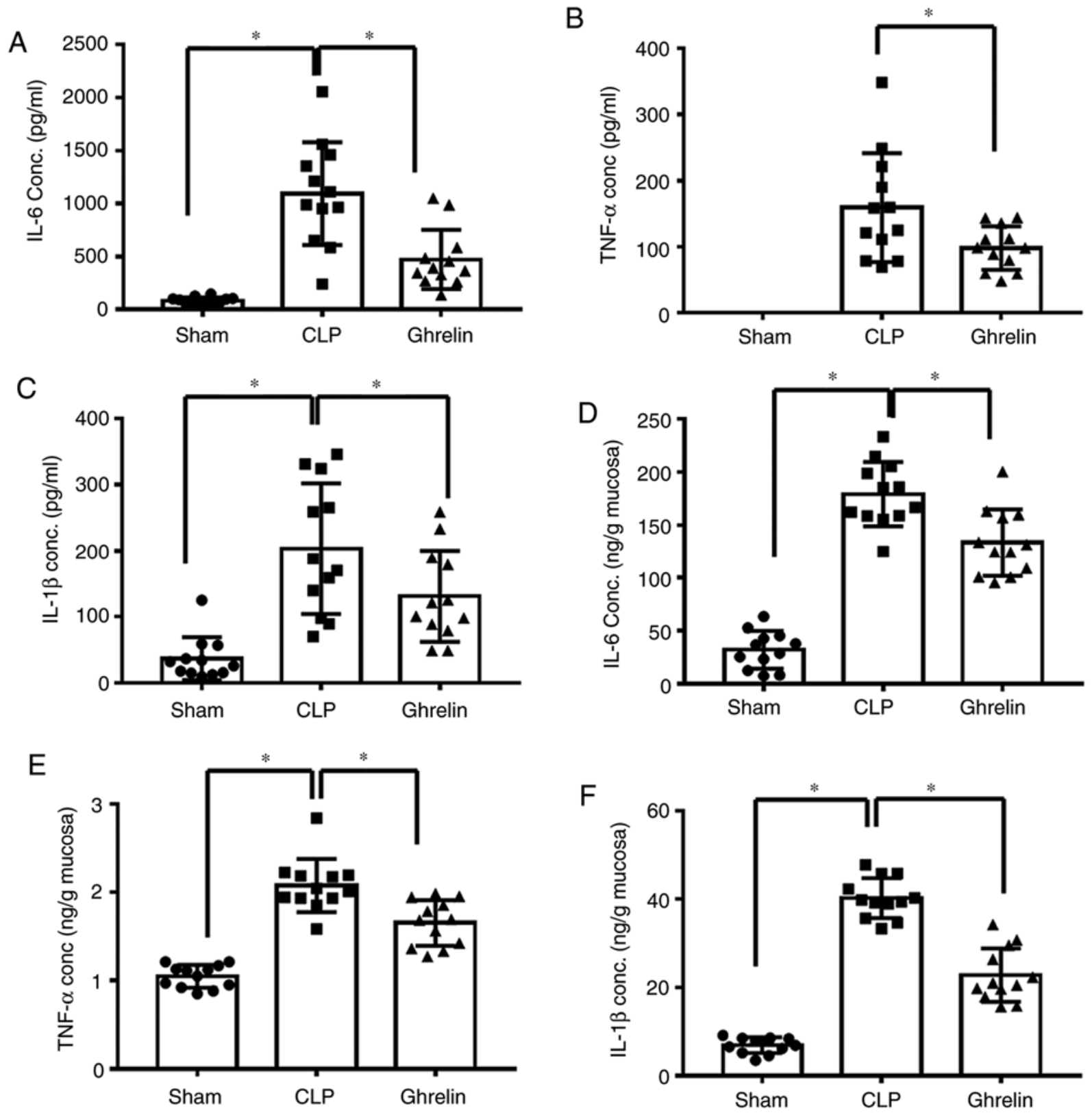

Figure 3. Pro-inflammatory cytokine levels in serum and tissues from sepsis model rats. Alterations in the levels of IL- $1 \beta$, TNF- $\alpha$ and IL-6 in the serum and the stomach lysate of sham-operated animals (Sham group), and animals with CLP treated with normal saline (CLP group) or ghrelin (ghrelin group) at $20 \mathrm{~h}$ post-surgery. (A) IL-6, (B) TNF- $\alpha$ and (C) IL-1 $\beta$ levels in serum. (D) IL-6, (E) TNF- $\alpha$ and (F) IL-1 $\beta$ levels in tissue from the stomach lysate. Data are presented as the mean \pm standard error ( $\mathrm{n}=12 /$ group) and compared by one-way analysis of variance and the Student-Newman-Keuls test. " $\mathrm{P}<0.05$, as indicated. IL, interleukin; TNF- $\alpha$, tumor necrosis factor- $\alpha$; CLP, cecal ligation and puncture; conc., concentration.

the CLP group (Fig. 2A and B). Ghrelin treatment restored the blood pressure and the blood flow to the stomach almost back to the level of the sham group, indicating that ghrelin treatment may be able to attenuate sepsis symptoms. Increased pro-inflammatory cytokine levels are considered to be another indicator of sepsis. The level of cytokines, including TNF- $\alpha$, IL-6 and IL-1 $\beta$, were examined in the circulation (Fig. 3A-C) and in the stomach tissue (Fig. 3D-F) of sepsis model rats. As shown in Fig. 3, the levels of the 3 proinflammatory cytokines were significantly increased in the CLP group when compared with that of the sham group, while administration of ghrelin reversed this CLP-induced increase, indicating that ghrelin may have a protective role during sepsis-induced systemic inflammatory response syndrome.
Apoptosis-associated protein expression profile in stomach тисоsa. Uncontrolled and abnormal inflammatory reactions in tissues can lead to cell apoptosis. As sepsis induced systemic inflammation in the present model, it was hypothesized that CLP may also affect cell apoptosis in the stomach mucosa. To validate this hypothesis, the expression of 3 representative apoptosis-associated proteins was assessed in the 3 experimental groups. Immunohistochemistry or immunofluorescent staining was used to detect the protein expression of $\mathrm{Bcl}-2$ and Bax, and cleaved caspase-3, respectively, in the stomach mucosa. The most striking result to emerge from the data, as shown in Fig. 4A, was that Bcl-2 and Bax expression was barely detectable in the rat gastric mucosal tissues in the sham group. CLP-induced sepsis decreased the level of Bcl-2 and 
A

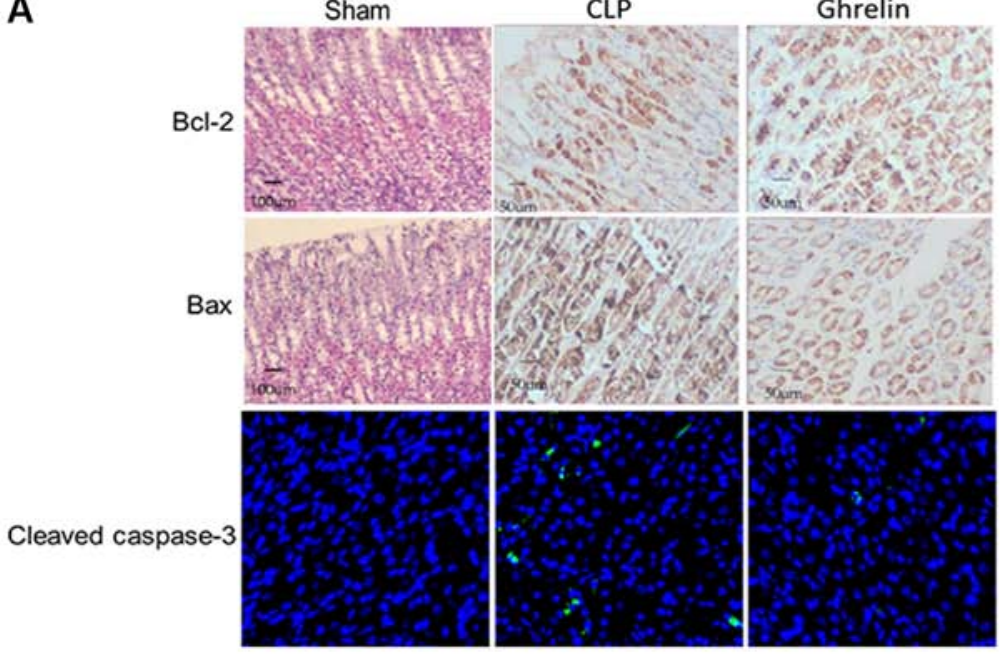

B

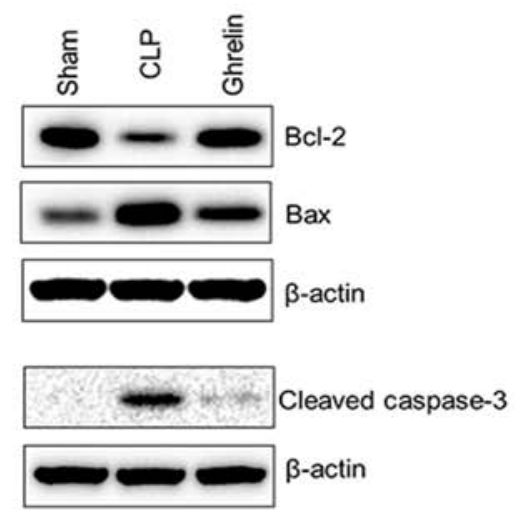

Figure 4. Effect of ghrelin on the expression levels of apoptosis-associated proteins in the sepsis model. (A) Representative immunohistochemistry staining in sham, CLP and ghrelin-treated rats (rows 1 and 2). Immunofluorescent staining for cleaved caspase-3 in the stomach (row 3). Green staining, cleaved caspase 3; blue staining, nuclear staining with DAPI. (B) Western blot analysis of Bcl-2, Bax and cleaved caspase- 3 in the sham, CLP and ghrelin-treated rats. $\beta$-actin was used as the loading control. The blots are representative of at least 3 independent experiments. CLP, cecal ligation and puncture; Bcl-2, B-cell lymphoma 2; Bax, Bcl-2-associated X.

A
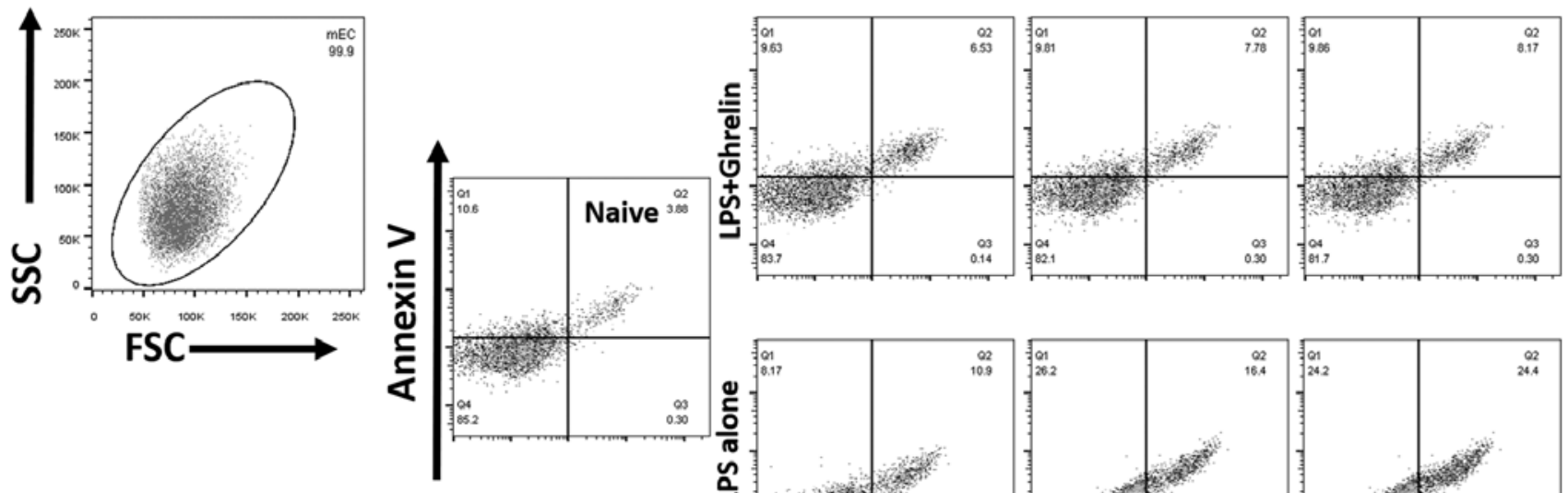

B
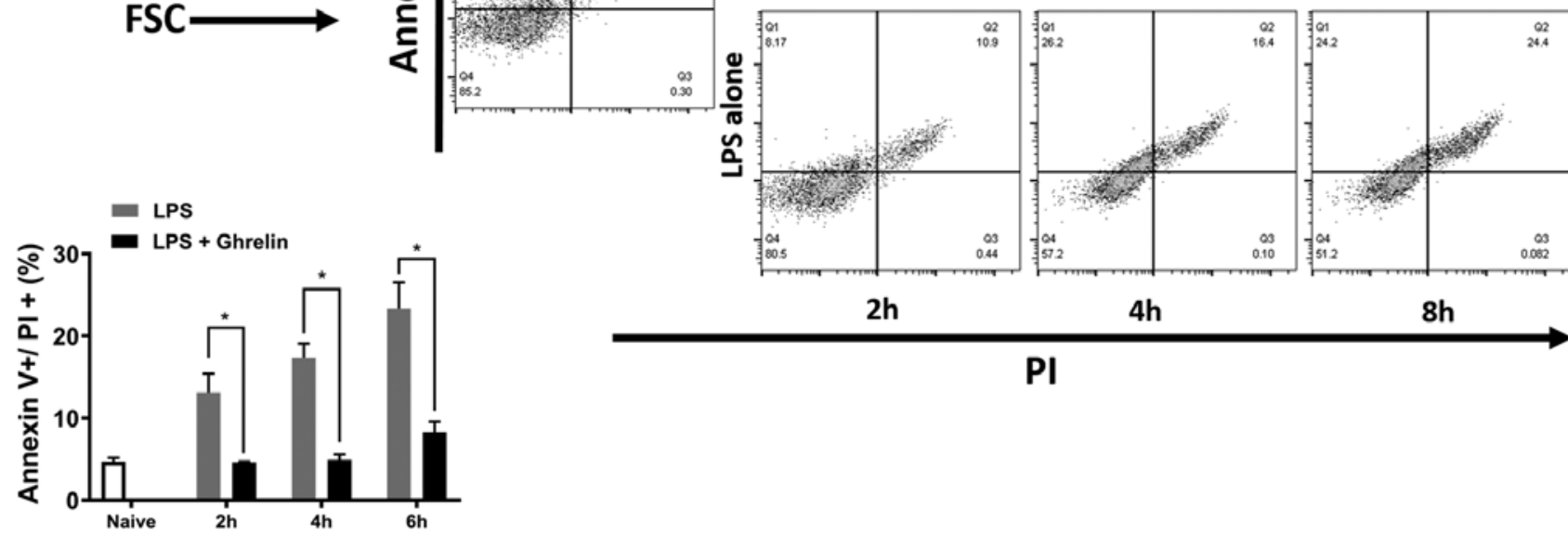

$2 \mathrm{~h}$

4h

$8 \mathrm{~h}$

PI

Figure 5. Ghrelin prevents LPS-induced GEC apoptosis. (A) Naïve GECs $\left(2 \times 10^{5}\right)$ were cultured in 24-well plates and stimulated by LPS with or without ghrelin. Following the 2, 4 and $8 \mathrm{~h}$ incubation periods, the (B) percentage of apoptotic GECs was assessed by staining the cells with Annexin V and PI followed by flow cytometric analysis. Data presented as the mean \pm standard error ( $\mathrm{n}=3 /$ group). ${ }^{*} \mathrm{P}<0.05$. LPS, lipopolysaccharide; GEC, gastric epithelial cell; PI, propidium iodide; FSC, forward scatter; SSC, side scatter.

increased the level of Bax in the stomach mucosa compared with that of the sham group, in terms of staining density and the number of stained cells. When ghrelin was administered to the CLP-induced sepsis rats, the staining of these 2 proteins was attenuated when compared with CLP alone. Consistently, cleaved caspase-3, a marker of cell apoptosis, exhibited the same trend (Fig. 4A). While CLP increased the cleaved caspase-3 level, application of ghrelin significantly downregulated its expression in the stomach mucosa. These observations were further validated and semi-quantified by western blotting. Stomach mucosa from the same rats was harvested as aforementioned, and lysates were blotted to determine the protein level of Bcl-2, Bax and cleaved caspase-3 (Fig. 4B). CLP significantly reduced the expression of $\mathrm{Bcl}-2$, and enhanced the pro-apoptotic proteins 
Bax and cleaved caspase- 3 compared with sham rats; whereas, ghrelin application reversed the effects of CLP on the expression of these apoptosis-associated proteins. Based on these results, it was hypothesized that ghrelin protected the stomach from CLP-induced sepsis injury by preventing the apoptosis of mucosal cells.

Ghrelin inhibits cell apoptosis in stomach mucosa in vitro. To further elucidate the role of ghrelin in stomach mucosa cell apoptosis, LPS, the trigger of septic shock, was used to induce cell apoptosis in vitro. Following LPS stimulation, GECs without ghrelin treatment exhibited a higher proportion of apoptotic cells (Annexin V and PI double positive) than the ghrelin treatment group, suggesting that ghrelin attenuates sepsis-induced injury to stomach epithelial cells (Fig. 5A and B). At each time point tested, LPS increased cell apoptosis when compared with the control group (naïve cells), which was significantly reduced by the addition of ghrelin.

\section{Discussion}

The aim of the present study was to explore the potential beneficial effect of ghrelin on sepsis symptoms in the gastrointestinal tract, including the gastric blood flow and the expression of Bcl-2 and Bax in gastric tissues. The results showed that ghrelin could promote blood flow in the stomach of rats with sepsis, and could upregulate the protein expression of Bcl-2 and downregulate the expression of Bax in gastric tissues. Ghrelin was first discovered by Kojima et al (32) in 1999. It is widely distributed in the body, including in the stomach, intestine and pituitary gland. Ghrelin regulates the secretion of many hormones (such as growth hormone, prolactin and adrenal gland hormones), maintains hormonal balance, promotes ingestion, decreases fat use, influences energy metabolism, regulates hemodynamic force, decreases average hemodynamic force, increases cardiac index, increases stroke volume, and regulates gastric motility and gastric acid secretion, all of which are associated with stomach functions $(18,25,33)$. In the present study, the CLP-induced sepsis group rats exhibited significantly decreased blood flow in the stomach greater curvature compared with the normal control group. In the ghrelin treatment group, the gastric blood flow was significantly higher than in the sepsis group, which suggested ghrelin may, at least in part, reverse the pathological changes caused by CLP-induced sepsis. These results support the findings of Wan et al (34). Their previous results indicated that ghrelin could increase autophagy in sepsis patients and alleviate the damage to the intestinal tract, suggesting that ghrelin had protective effects on the gastrointestinal tract (34). These results are consistent with those obtained by other previous studies, which reported that plasma levels of ghrelin were significantly reduced after CLP, that ghrelin administration improves organ blood flow by inhibiting nuclear factor- $\mathrm{\kappa} B$, it increases tissue perfusion in sepsis by increasing cardiac output and cardiac output, and it decreased vascular resistance by decrease norepinephrine level $(31,35,36)$. As far as we known, ghrelin can regulate energy balance in addition to appetite. The sepsis rat in a negative energy balance state requires more energy, which may lead to the upregulation of ghrelin (37). The sepsis rat may have a poor appetite, which is the result of the downregulation of ghrelin. So there may be some degree of balance between the up- and downregulation of ghrelin in septic rats, and the end results downregulate ghrelin; however, appetite cannot regulate ghrelin levels (38), and Ariyasu et al (39) demonstrated that ghrelin secretion even increased in anorexia, which proved the administration of ghrelin did not necessarily lead to the amelioration of appetite. In addition, ghrelin treatment significantly increased adenosine triphosphate values and improved tissue histology in septic rats (40). Therefore, we believe that the sepsis itself lead to the ischemia of stomach greater curvature by downregulating ghrelin as opposed to other reasons. Furthermore, the present results are similar to those of Lyra Junior et al (41). Their previous results indicated that ghrelin can increase local nitric oxide release and reduce tissue ischemia of gut.

$\mathrm{Bcl}-2$ is known to be an important apoptosis regulator $(42,43)$. The Bcl-2 family members function as dimers; whereby, $\mathrm{Bcl}-2 / \mathrm{Bcl}-2, \mathrm{Bcl}-2 / \mathrm{Bax}$ and $\mathrm{Bcl}-2 / \mathrm{Bcl}-\mathrm{xl}$ dimers inhibit apoptosis signaling, and $\mathrm{Bax} / \mathrm{Bax}, \mathrm{Bax} / \mathrm{Bad}$ and $\mathrm{Bcl}-2 / \mathrm{Bcl}-\mathrm{xs}$ dimers promote apoptosis $(42,43)$. The interaction between $\mathrm{Bcl}-2$ family proteins regulates the survival and apoptosis of cells $(44,45)$. In the present study, in the normal control group, Bcl-2 and Bax were not expressed in rat gastric mucosa and were barely detectable in the gastric mucosa tissues of sham group rats. Bax protein expression was higher than the Bcl-2 levels in the CLP-induced sepsis group; however, following ghrelin treatment, Bcl-2 exhibited strong positive expression in the gastric mucosa, and the number of Bcl-2-positive cells was increased when compared with that of Bax. The results suggested that ghrelin treatment might inhibit apoptosis in gastric mucosa tissue.

Taken together, the results of the present study revealed that ghrelin has the ability to increase blood flow in the gastrointestinal tract in a sepsis model and regulate the expressions of apoptosis-associated factors in gastric tissues, inhibiting the expression of pro-apoptosis proteins and promoting the expression of anti-apoptosis proteins. Nevertheless, it is unclear whether the apoptotic factors can be directly regulated by ghrelin. It has been reported that the effect of ghrelin on the gastrointestinal tract is predominantly mediated through the cholinergic pathway (34). Another study reported that the protective effect of ghrelin on the gastrointestinal tract was due to the increased expression of LC3, Autophagy-related 7 and Beclin1 (46). Additional studies are still necessary to determine the exact mechanisms of ghrelin in the gastrointestinal tract in the context of sepsis. In conclusion, the beneficial effects of ghrelin include the promotion of blood flow in the stomach of rats with sepsis and the prevention of stomach mucosa cell apoptosis, potentially through the regulation of $\mathrm{Bcl}-2$, Bax and caspase- 3 protein expression.

\section{Acknowledgements}

Not applicable.

\section{Funding}

The present study was supported by Natural Science Foundation of Gansu Province (grant nos. 1308RJZA240-01 and 1506RJZA255). 


\section{Availability of data and materials}

The datasets used and/or analyzed during the current study are available from the corresponding author on reasonable request.

\section{Authors' contributions}

$\mathrm{BL}$ and QL performed the experiments and analyzed the data. LL and HG collected the samples, analyzed the data, and reviewed and edited the manuscript. YL provided the reagents and analyzed the data. BL, HG and YL also contributed to the discussion, and reviewed and edited the manuscript. BL and YL designed the experiments, summarized the data and wrote the manuscript. All authors read and approved the final manuscript.

\section{Ethics approval and consent to participate}

All procedures involving mice were approved by the Institutional Animal Care and Use Committee of Lanzhou University (Lanzhou, China).

\section{Patient consent for publication}

Not applicable.

\section{Competing interests}

The authors declare that they have no competing interests.

\section{References}

1. Lever A and Mackenzie I: Sepsis: Definition, epidemiology, and diagnosis. BMJ 335: 879-83, 2007.

2. Martin GS: Sepsis, severe sepsis and septic shock: Changes in incidence, pathogens and outcomes. Expert Rev Anti Infect Ther 10: 701-706, 2012.

3. Singer M, Deutschman CS, Seymour CW, Shankar-Hari M, Annane D, Bauer M, Bellomo R, Bernard GR, Chiche JD, Coopersmith CM, et al: The third international consensus definitions for sepsis and septic shock (Sepsis-3). JAMA 315: 801-810, 2016.

4. Kennelly PJ and Martin-Loeches I: Long term mortality following sepsis. Ann Transl Med 4: 387, 2016.

5. Lang CH, Bagby GJ, Ferguson JL and Spitzer J: Cardiac output and redistribution of organ blood flow in hypermetabolic sepsis. Am J Physiol 246: R331-R337, 1984.

6. Moore JX, Donnelly JP, Griffin R, Howard G, Safford MM and Wang HE: Defining sepsis mortality clusters in the united states. Crit Care Med 44: 1380-1387, 2016.

7. Dashwood AM, Mason R, Jennings C and Dhillon P: Hepatic portal venous gas with associated bowel ischaemia and intra-abdominal sepsis after recent chemotherapy. BMJ Case Rep 2016: pii: bcr201521356, 2016.

8. Zhang T, Yang J, Ding C, Li Y, Gu L, Wei Y, Cao L, Gong J, Zhu W, Li N and Li J: Preoperative intra-abdominal sepsis, not penetrating behavior itself, is associated with worse postoperative outcome after bowel resection for crohn disease: A Retrospective Cohort Study. Medicine (Baltimore) 94: e1987, 2015.

9. Hiltebrand LB, Krejci V, tenHoevel ME, Banic A and Sigurdsson GH: Redistribution of microcirculatory blood flow within the intestinal wall during sepsis and general anesthesia. Anesthesiology 98: 658-669, 2003.

10. Albanèse $J$, Leone $M$, Delmas A and Martin C: Terlipressin or norepinephrine in hyperdynamic septic shock: A prospective, randomized study. Crit Care Med 33: 1897-1902, 2005.

11. Patel BM, Chittock DR, Russell JA and Walley KR: Beneficial effects of short-term vasopressin infusion during severe septic shock. Anesthesiology 96: 576-582, 2002.
12. van Haren FM, Rozendaal FW and van der Hoeven JG: The effect of vasopressin on gastric perfusion in catecholamine-dependent patients in septic shock. Chest 124: 2256-2260, 2003.

13. Janiuk I, Kaleczyc J and Kasacka I: Ghrelin-immunoreactive cells in the gastrointestinal tract of hypertensive rats. Folia Histochem Cytobiol 54: 181-185, 2016.

14. Sakata I, Nakamura K, Yamazaki M, Matsubara M, Hayashi Y, Kangawa K and Sakai T: Ghrelin-producing cells exist as two types of cells, closed- and opened-type cells, in the rat gastrointestinal tract. Peptides 23: 531-536, 2002.

15. Sakata I and Sakai T: Ghrelin cells in the gastrointestinal tract. Int J Pept 2010: pii: 945056, 2010.

16. Shao Y, Liu S, Tang X, Gao J, Wu G and Li Z: Ontogeny of ghrelin mRNA expression and identification of ghrelin-immunopositive cells in the gastrointestinal tract of the Peking duck, Anas platyrhynchos. Gen Comp Endocrinol 166: 12-18, 2010.

17. Wang JX, Peng KM, Liu H, Song H, Chen X and Liu M: Distribution and developmental changes in ghrelin-immunopositive cells in the gastrointestinal tract of African ostrich chicks. Regul Pept 154: 97-101, 2009.

18. Kaplan RC, Strizich G, Aneke-Nash C, Dominguez-Islas C, Bůžková P, Strickler H, Rohan T, Pollak M, Kuller L, Kizer JR, et al: Insulinlike growth factor binding protein-1 and ghrelin predict health outcomes among older adults: Cardiovascular Health Study Cohort. J Clin Endocrinol Metab 102: 267-278 2017.

19. Mansson JV, Alves FD, Biolo A and Souza GC: Use of ghrelin in cachexia syndrome: A systematic review of clinical trials. Nutr Rev 74: 659-669, 2016.

20. Sominsky L, Ziko I, Nguyen TX, Andrews ZB and Spencer SJ: Early life disruption to the ghrelin system with over-eating is resolved in adulthood in male rats. Neuropharmacology 113: 21-30, 2017

21. Zhou D, Jiang X, Jian W, Zheng L, Lu L and Zheng C: Comparing the effectiveness of total gastrectomy and gastric bypass on glucose metabolism in diabetic rats. Obes Surg 26: 119-125, 2016.

22. Konturek PC, Brzozowski T, Pajdo R, Nikiforuk A, Kwiecien S, Harsch I, Drozdowicz D, Hahn EG and Konturek SJ: Ghrelin-a new gastroprotective factor in gastric mucosa. J Physiol Pharmacol 55: 325-336, 2004.

23. Bilgin HM, Tumer C, Diken H, Kelle M and Sermet A: Role of ghrelin in the regulation of gastric acid secretion involving nitrergic mechanisms in rats. Physiol Res 57: 563-568, 2008.

24. Park JM, Kakimoto T, Kuroki T, Shiraishi R, Fujise T, Iwakiri R and Fujimoto K: Suppression of intestinal mucosal apoptosis by ghrelin in fasting rats. Exp Biol Med (Maywood) 233: 48-56, 2008.

25. Wei C, Louis H, Schmitt M, Albuisson E, Orlowski S, Levy B and Kimmoun A: Effects of low doses of esmolol on cardiac and vascular function in experimental septic shock. Criti Care 20: 407, 2016

26. Chen YK, Xu YK, Zhang H, Yin JT, Fan X, Liu DD, Fu HY and Wan B: Emodin alleviates jejunum injury in rats with sepsis by inhibiting inflammation response. Biomed Pharmacother 84 : 1001-1007, 2016.

27. Kouno T, Akiyama N, Fujieda K, Nanchi I, Okuda T, Iwasaki T, Oka S and Yukioka H: Reduced intake of carbohydrate prevents the development of obesity and impaired glucose metabolism in ghrelin O-acyltransferase knockout mice. Peptides 86: 145-152, 2016.

28. Miyatake Y, Shiuchi T, Mawatari K, Toda S, Taniguchi Y, Futami A, Sato F, Kuroda M, Sebe M, Tsutsumi R, et al: Intracerebroventricular injection of ghrelin decreases wheel running activity in rats. Peptides 87: 12-19, 2017.

29. Zavros Y, Van Antwerp M and Merchant JL: Use of flow cytometry to quantify mouse gastric epithelial cell populations. Dig Dis Sci 45: 1192-1199, 2000.

30. Zeineldin M and Neufeld K: Isolation of epithelial cells from mouse gastrointestinal tract for western blot or RNA analysis. Bio Protoc 2: e292, 2012.

31. Wu R, Dong W, Zhou M, Zhang F, Marini CP, Ravikumar TS and Wang P: Ghrelin attenuates sepsis-induced acute lung injury and mortality in rats. Am J Respir Crit Care Med 176: 805-813, 2007.

32. Kojima M, Hosoda H, Date Y, Nakazato M, Matsuo H and Kangawa K: Ghrelin is a growth-hormone-releasing acylated peptide from stomach. Nature 402: 656-660, 1999.

33. Shirshev SV, Nekrasova IV, Orlova EG and Gorbunova OL: Roles of leptin and ghrelin in the regulation of the phenotype and cytokine production by NK cells from peripheral blood. Dokl Biol Sci 470: 249-252, 2016. 
34. Wan SX, Shi B, Lou XL, Liu JQ, MA GG, Liang DY and Ma S: Ghrelin protects small intestinal epithelium against sepsis-induced injury by enhancing the autophagy of intestinal epithelial cells. Biomed Pharmacother 83: 1315-1320, 2016.

35. Wu R, Dong W, Zhou M, Cui X, Hank Simms H and Wang P: Ghrelin improves tissue perfusion in severe sepsis via downregulation of endothelin-1. Cardiovasc Res 68: 318-326, 2005.

36. Jacob A, Wu R, Zhou M, Coppa GF and Wang P: Mechanism of the inhibitory effect of ghrelin in sepsis. Hepat Med 2: 33-38, 2010.

37. Pradhan G, Samson SL and Sun YX: Ghrelin: Much more than a hunger hormone. Curr Opin Clin Nutr Metab Care 16: 619-624, 2013.

38. Diz-Chaves Y: Ghrelin, appetite regulation, and food reward: Interaction with chronic stress. Int J Pept 2011: 898450, 2011.

39. Ariyasu H, Takaya K, Tagami T, Ogawa Y, Hosoda K, Akamizu T, Suda M, Koh T, Natsui K, Toyooka S, et al: Stomach is a major source of circulating ghrelin, and feeding state determines plasma ghrelin-like immunoreactivity levels in humans. J Clin Endocrinol Metab 86: 4753-4758, 2001.

40. Yorulmaz H, Ozkok E, Ates G, Aksu A, Balkıs N and Tamer S: Ghrelin: Impact on muscle energy metabolism in sepsis. Int J Pept Res Ther 24: 259-264, 2018.

41. Lyra Junior HF, Rodrigues IK, Schiavon LL and D Acâmpora AJ: Ghrelin and gastrointestinal wound healing. A new perspective for colorectal surgery. Acta Cir Bras 33: 282-294, 2018.
42. Czabotar PE, Lessene G, Strasser A and Adams JM: Control of apoptosis by the BCL-2 protein family: Implications for physiology and therapy. Nat Rev Mol Cell Biol 15: 49-63, 2014.

43. Tsujimoto Y: Role of Bcl-2 family proteins in apoptosis: Apoptosomes or mitochondria? Genes Cells 3: 697-707, 1998.

44. An HM, Tan YL, Shi J, Wang Z, Lv MH, Soares JC, Zhou D, Yang F and Zhang XY: Ginkgo biloba leaf extract and alpha-tocopherol attenuate haloperidol-induced orofacial dyskinesia in rats: Possible implication of antiapoptotic mechanisms by preventing $\mathrm{Bcl}-2$ decrease and Bax elevation. Phytomedicine 23: 1653-1660, 2016.

45. Jiang Z, Liu X, Chang K, Liu X and Xiong J: Allyl Isothiocyanate inhibits the proliferation of renal carcinoma cell line GRC-1 by inducing an imbalance between $\mathrm{Bcl} 2$ and Bax. Med Sci Monit 22: 4283-4288, 2016.

46. Yorulmaz H, Ozkok E, Erguven M, Ates G, Aydin I and Tamer S: Effect of simvastatin on mitochondrial enzyme activities, ghrelin, hypoxia-inducible factor $1 \alpha$ in hepatic tissue during early phase of sepsis. Int J Clin Exp Med 8: 3640-3650, 2015.

This work is licensed under a Creative Commons Attribution-NonCommercial-NoDerivatives 4.0 International (CC BY-NC-ND 4.0) License. 